\title{
ENSINO EM PARASITOLOGIA: AÇÃO EXTENSIONISTA COM CRIANÇAS EM IDADE ESCOLAR
}

\section{TEACHING IN PARASITOLOGY: EXTENSIONIST ACTION WITH SCHOOL CHILDREN}

\author{
Karen Ferraz Faria* \\ Kelem Cristina Pereira Mota** \\ Camila Oliveira Silva** \\ Marco Miguel de Oliveira**** \\ Iasmin Aparecida Cunha Araújo ${ }^{* * * * *}$ \\ Gabriela Gonçalves Mendes****** \\ Gabriela Gonçalves Mendes
Douglas Alves Pereira* \\ Márcia Cristina Cury
}

\section{RESUMO:}

O conhecimento acerca das parasitoses é importante, principalmente em crianças no período escolar, as quais são mais suscetíveis devido ao amadurecimento do sistema imune e maior exposição aos parasitos. O objetivo deste estudo foi promover ações com ênfase na Educação para a Saúde em escolas públicas de Uberlândia, Minas Gerais, Brasil, a respeito de algumas parasitoses, bem como a prevenção dessas doenças. Esta ação foi desenvolvida entre agosto e setembro de 2017, realizando palestras expositivainformativas que abordaram as principais parasitoses que acometem crianças em idade escolar, dando enfoque na transmissão, sintomas e medidas profiláticas. $O$ público atingido diretamente foi de 258 alunos e foi possível constatar, através da análise dos questionários aplicados, um processo de ensino-aprendizagem satisfatório relacionado à apropriação do conhecimento sobre as doenças parasitárias. Pode-se concluir que acões extensionistas são importantes, pois através da educação em saúde, os alunos ampliam seus conhecimentos, colocando-os em prática no seu dia a dia, aprimorando sua qualidade de vida.

Palavras-chave: Parasitologia; Educação em Saúde; Extensão; Prevenção.

\begin{abstract}
:
Knowledge about parasites is important, especially in the school environment, as schoolchildren are more susceptible due to the maturation of the immune system and for being more exposed to parasites. The objective of this study was to promote the actions focusing on Health Education in public schools in Uberlandia, Minas Gerais, Brazil, regarding some parasites, as well as the prevention of these diseases. This action was carried out from August and September 2017 and included expository-informational lectures. Such presentations addressed the main parasitic diseases affecting schoolchildren, focusing on transmission, symptoms and prophylactic measures. The directly targeted audience comprised 258 students and the analysis of the questionnaires applied showed satisfactory learning related to the pupils' appropriation of knowledge about parasitic diseases. In conclusion, extension actions are important because through health education, students expand their knowledge and put it into practice, improving their quality of life.
\end{abstract}

Keywords: Parasitology; Health Education; Extension; Prevention.

\footnotetext{
* Aluna de Doutorado da Universidade Federal de Uberlândia (UFU), Uberlândia - MG, Brasil. E-mail: karen.ferraz.itba@hotmail.com ** Aluna de Doutorado da Universidade Federal de Uberlândia (UFU), Uberlândia - MG, Brasil. E-mail: kelem.mota@hotmail.com *** Aluna de Doutorado da Universidade Federal de Uberlândia (UFU), Uberlândia - MG, Brasil. E-mail: camila.sngpc@hotmail.com **** Aluno de Doutorado da Universidade Federal de Uberlândia (UFU), Uberlândia - MG, Brasil. E-mail: marcomiguel03@gmail.com ${ }^{* * * * *}$ Aluna de Doutorado da Universidade Federal de Uberlândia (UFU), Uberlândia - MG, Brasil. E-mail: iasminaraujo2006@hotmail.com ****** Mestrado. Universidade Federal de Uberlândia (UFU), Uberlândia - MG, Brasil. E-mail: ggm-gabi@hotmail.com ******* Mestrado, Universidade Federal de Uberlândia (UFU), Uberlândia - MG, Brasil. E-mail: douglas.vet1@gmail.com ${ }^{* * * * * * *}$ Professora da Universidade Federal de Uberlândia (UFU), Uberlândia - MG, Brasil. E-mail: marcia.cury@ufu.b
} 


\section{Introdução}

Parasitoses constituem um sério problema de saúde pública e estão entre os patógenos que mais acometem os seres humanos, sendo importantes causas de morbidade e mortalidade entre crianças e em indivíduos imunocomprometidos (KUMAR et al., 2017).

Infecções causadas por parasitos intestinais afetam cerca de 3,5 bilhões de pessoas no mundo, e como consequência causam diversas enfermidades em aproximadamente 880 milhões de indivíduos (WHO, 2018). As distribuições geográficas e espaciais dos parasitos sofrem variações de acordo com a região, clima, condições de saneamento básico, nível socioeconômico e hábitos de higiene (BETHONY et al., 2006).

Doenças parasitárias acometem, principalmente, crianças em idade escolar devido ao amadurecimento do sistema imune, pouco conhecimento sobre os princípios básicos de higiene (como o hábito de lavar as mãos) e por estarem mais expostas aos parasitos, estando suscetíveis às infecções e a reinfecções (GALVANI, 2005). A aglomeração leva a disseminação desses patógenos (MONTEIRO et al., 2009).

Apesar da qualidade de vida da população brasileira ter melhorado, as parasitoses continuam acometendo indivíduos de diversas faixas etárias e regiões. Dados de vários estudos demonstram prevalências em Minas Gerais entre 24,6 a 64,5\% (MENEZES et al., 2008; BEINNER et al., 2006; NOBRE et al., 2013; PEREIRA et al., 2016), e no município de Uberlândia de $29,3 \%$ a $60 \%$, em indivíduos de diferentes faixas etárias, entre as quais as crianças são mais atingidas (FERREIRA, et al., 2003; REZENDE et al., 1997; SILVA et al., 2003; GONÇALVES et al., 2011).

Dentre os parasitos que mais acometem esses indivíduos, destacam-se ectoparasitos como Pediculus spp. (piolho de cabeça) e Tunga penetrans (bicho-depé, principalmente em escolas rurais), bem como enteroparasitos, como Giardia duodenalis, Cryptosporidium parvum, ancilostomídeos e ascaridídeos (MENDES et al., 2017; GONÇALVES et al. 2011; MACHADO et al., 2008).

A transmissão de parasitos é influenciada, principalmente, pelos hábitos de higiene do indivíduo e a prevenção é a melhor forma de evitar a infecção. Sendo assim, práticas educacionais relacionadas à saúde, inseridas no ambiente escolar, podem melhorar o conhecimento da população sobre os fatores de risco que levam a essas infecções (UCHOA et al., 2001).

Dessa forma, a participação da Universidade pode contribuir na busca da melhoria e/ou soluções para diversos problemas sociais, seja pelo ensino, pesquisa e ações extensionistas (MACIEL, 2010). A maior dificuldade observada no contexto populacional está relacionada à escassez de informações em relação à disseminação, transmissão e profilaxia das parasitoses. Ações que aproximem a sociedade desses conhecimentos são importantes para futuros programas e suas aplicações, de profilaxia e combate. Diante disto, a extensão universitária é fundamental para o acesso democrático ao conhecimento (MOITA; ANDRADE, 2009)

O presente estudo teve como objetivo promover ações com ênfase na Educação para a Saúde em escolas do ensino básico do município de Uberlândia (MG), a respeito de parasitoses comumente existentes no ambiente escolar, bem como suas principais formas de prevenção.

\section{Metodologia}

\section{Desenho do estudo}

Estudo não randomizado, baseado na avaliação da apropriação de conhecimento dos envolvidos antes e após o desenvolvimento das atividades educativas.

\section{Local do estudo}

As ações foram desenvolvidas no município de Uberlândia, estado de Minas Gerais, localizada na região sudeste do Brasil. A população estimada é de 676.613 habitantes, distribuída em uma área total de 4.115,206 km² (BRASIL, 2018). O município possui 54 escolas da rede municipal de ensino fundamental; 37 escolas municipais de educação infantil e 70 escolas estaduais com nível fundamental e médio (PMU, 2018; SRE, 2018).

As atividades foram realizadas com alunos de instituições públicas de ensino, escolhidas aleatoriamente, contemplando as diferentes faixas etárias. Dentre essas, duas eram escolas de ensino básico da zona urbana, uma escola de ensino básico localizada em um distrito do município (zona rural) e uma creche municipal.

\section{Protocolo e instrumento do estudo}

O presente trabalho foi executado por um grupo de pós-graduandos do Programa de Imunologia e Parasitologia Aplicadas, da Universidade Federal de Uberlândia, sendo aprovado pela Pró-Reitoria de Extensão, Cultura e Assuntos Estudantis - UFU, sob os registros 15735,15530 e 15525 .

Este trabalho foi desenvolvido nos meses de agosto e setembro de 2017. Inicialmente, foi realizado contato com responsáveis das escolas de educação infantil, ensino fundamental e médio por telefone, para apresentação sucinta do projeto e objetivos, a fim de convidá-los a participarem. Após a aceitação dos responsáveis das instituições de ensino, foram agendadas reuniões nas quais foi apresentado o projeto de forma detalhada; em seguida, as ações foram previamente planejadas e, então, definidas datas e horários viáveis para sua execução.

Para a avaliação da eficácia das atividades, foi aplicado questionário investigativo (pré-teste), a fim de averiguar o conhecimento prévio dos alunos sobre parasitoses de forma geral. As questões avaliadas no questionário foram:

\section{Questão 1: O que são parasitoses?}

Questão 2: Quais parasitos você conhece? Como eles são transmitidos?

Questão 3: Você sabe qual a prevenção para essas doenças? 
Questionários são definidos por Chizzotti (2001) como um conjunto de questões sobre o problema, previamente elaboradas, para serem respondidas por um interlocutor, por escrito ou oralmente, podendo ter questões fechadas ou abertas, com o objetivo de obter dos informantes respostas sobre itens que constituem o tema da pesquisa.

Após aplicação do questionário, foram realizadas palestras expositiva-informativas sobre parasitoses, abordando transmissão, ciclo biológico do parasito, sinais e sintomas da doença e medidas profiláticas individuais e coletivas. Os parasitos abordados foram: Taenia saginata, Taenia solium, Giardia duodenalis, Cryptosporidium parvum, Pediculus spp., Tunga penetrans, Ancylostoma duodenale, Necator americanus e Ascaris lumbricoides. Tais espécies de parasitos foram escolhidas por serem as que mais acometem indivíduos em idade escolar (GONCCALVES et al., 2011; MACHADO et al., 2008; MENDES et al., 2017; REZENDE et al., 1997; SILVA et al., 2003).

O uso de palestras para o ensino do tema foi baseado na literatura, por contribuir na construção da autonomia do aluno, incentivando-o a desenvolver habilidades de pesquisa, comunicação e argumentação oral (PAIM; IAPPE; ROCHA, 2015).

As palestras foram realizadas com auxílio de datashow e banners ilustrativos. Após o desenvolvimento das atividades, foi aplicado novamente o mesmo questionário (pós-teste) aos mesmos alunos para avaliar a evolução no que se refere à apropriação de informações referentes aos temas abordados. Também foram entregues aos envolvidos cartilhas educativas com informações e imagens referentes ao tema, evidenciando, principalmente, medidas profiláticas.

Para as crianças da creche municipal e da escola rural, foram elaboradas atividades teatrais e contação de histórias, abordando, principalmente, hábitos de higiene apropriados para evitar infecções parasitárias. Estas atividades foram elaboradas a partir de materiais disponíveis 'online', incluindo as histórias intituladas "Maria coça-coça" e "Tânia, a tênia solitária" (MASSARA et al., 2018).

\section{Análise do questionário}

As respostas do questionário foram avaliadas quanto à porcentagem de citações que remetiam à: (i) "doenças causadas por parasitos" e "outra resposta" na questão 1; (ii) "um parasito e desconhecimento da forma de transmissão", "dois ou mais parasitos e desconhecimento das formas de transmissão", "um parasito e sua forma de transmissão", "dois ou mais parasitos e suas formas de transmissão", "forma de transmissão" e "outra resposta" na questão 2; (iii) "verme", "ectoparasito", "protozoário", "mais de um grupo de parasitos" e "outra resposta" na questão 2; (iv)"uma medida profilática", "duas ou mais medidas profiláticas" e "outra resposta" na questão 3. Nos casos onde a pergunta foi deixada em branco, a mesma foi incluída na categoria "não respondida". Os dados foram expressos em médias correspondentes à quantidade de respostas referentes a determinada categoria pelo número total de participantes na atividade, sendo os gráficos gerados no GraphPad®Instat 6 (GraphPad Software Inc., EUA).

\section{Resultados e discussão}

Nas ações desenvolvidas em escolas estaduais de ensino fundamental e médio, o público-alvo atingido diretamente foi de 258 alunos.

Desde o início da apresentação, quando citado o tema que seria abordado, percebeu-se que os alunos se interessaram, participando ativamente, fazendo questionamentos e relatando vivências.

O conhecimento prévio dos alunos sobre "o que são parasitoses" (questão 1) demonstrou ser baixo, conforme a análise do pré-questionário, sendo observado que, antes do desenvolvimento das ações, 54,21\% (135/249) dos estudantes de todas as escolas participantes responderam corretamente a pergunta; 3,61\% (9/249) escreveram outras respostas e 42,16\% (105/249) não souberam responder. Em comparação, ao se avaliar o mesmo questionário aplicado após o desenvolvimento das ações, observou-se aumento na quantidade de alunos que souberam responder a pergunta de forma correta $(82,55 \%$ [213/258]), enquanto $10,07 \%$ (26/258) citaram outras respostas e 7,36\% $(19 / 258)$ não souberam responder (Figura 1).

Figura 1 - Respostas dos alunos de ensino básico das escolas do município de Uberlândia, Minas Gerais, Brasil, no pré-teste (coluna tracejada) e pósteste (coluna preta) em relação a pergunta: "O que são parasitoses?" (Questão 1).

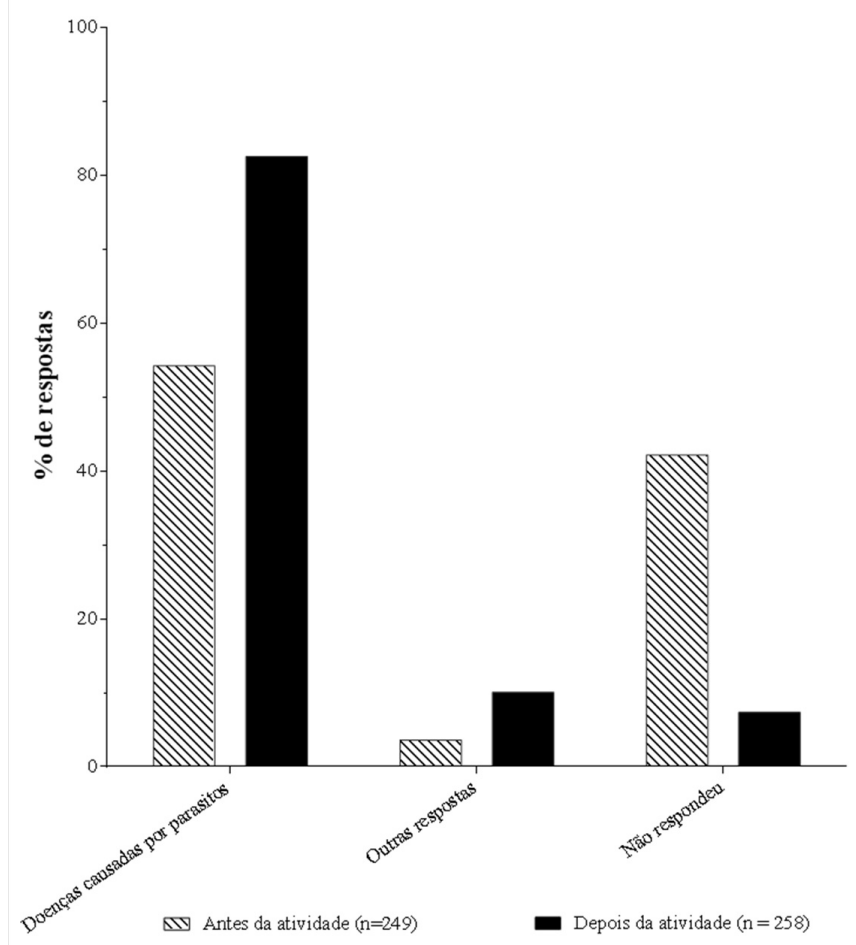

Fonte: Autores.

As palestras ministradas sobre as principais parasitoses tiveram impacto positivo, enriquecendo os alunos em relação ao conhecimento específico, uma vez que foi observado progresso nas respostas dos questionários. Atualmente, vários recursos de ensino, como jogos, brincadeiras, dentre outros, estão disponíveis para auxiliar os professores. Esses contribuem na aprendizagem dos alunos, de forma ilustrativa e próxima à realidade (DIAS; KOVALICZN, 2014; LEITE, 2011). A aula expositiva é importante ferramenta educacional, mas quando aliada a outras possibilidades, os resultados tornam-se mais significativos (ALVES et al., 2014).

No que concerne à transmissão dos parasitos e quais parasitos os envolvidos conheciam (Questão 2), 
percebeu-se a dificuldade dos alunos no pré-teste, uma vez que $20,88 \%(52 / 249)$ não conheciam formas de transmissão das parasitoses, porém, desses, 59,61\% (31/52) souberam citar um exemplo de parasito e $40,38 \% \quad(21 / 52)$ dois ou mais exemplos. A porcentagem de alunos que souberam citar uma forma de transmissão correta foi de 36,54\% (91/249), desses, $52,74 \%$ (48/91) citaram um exemplo de parasito, $18,68 \%$ (17/91) dois ou mais parasitos, 28,57\% (26/91) não conheciam o parasito, somente a transmissão. Ainda, 19,78\% (18/249) escreveram outras respostas e $35,34 \%(88 / 249)$ não souberam responder à questão. $\mathrm{Na}$ avaliação do pós-questionário dessa mesma pergunta, $66,27 \% \quad(171 / 258)$ dos participantes responderam ao menos uma forma de transmissão, indicando que houve uma apropriação do conhecimento acerca do tema abordado. Dentro desse número de alunos, 59,64\% (102/171) foram capazes de citar de 2 a 3 exemplos de parasitos, 35,67\% (61/171) apenas 1 e 4,67\% (8/171) não sabiam dar exemplos. Dos $29,84 \%(77 / 258)$ que não conheciam formas de transmissão, 32,46\% (25/77) citaram um exemplo de parasito e $67,53 \%(52 / 77)$ dois ou mais parasitos, $1,16 \%(3 / 258)$ deram outras respostas e $2,71 \%(7 / 258)$ não responderam à questão (Figura 2).

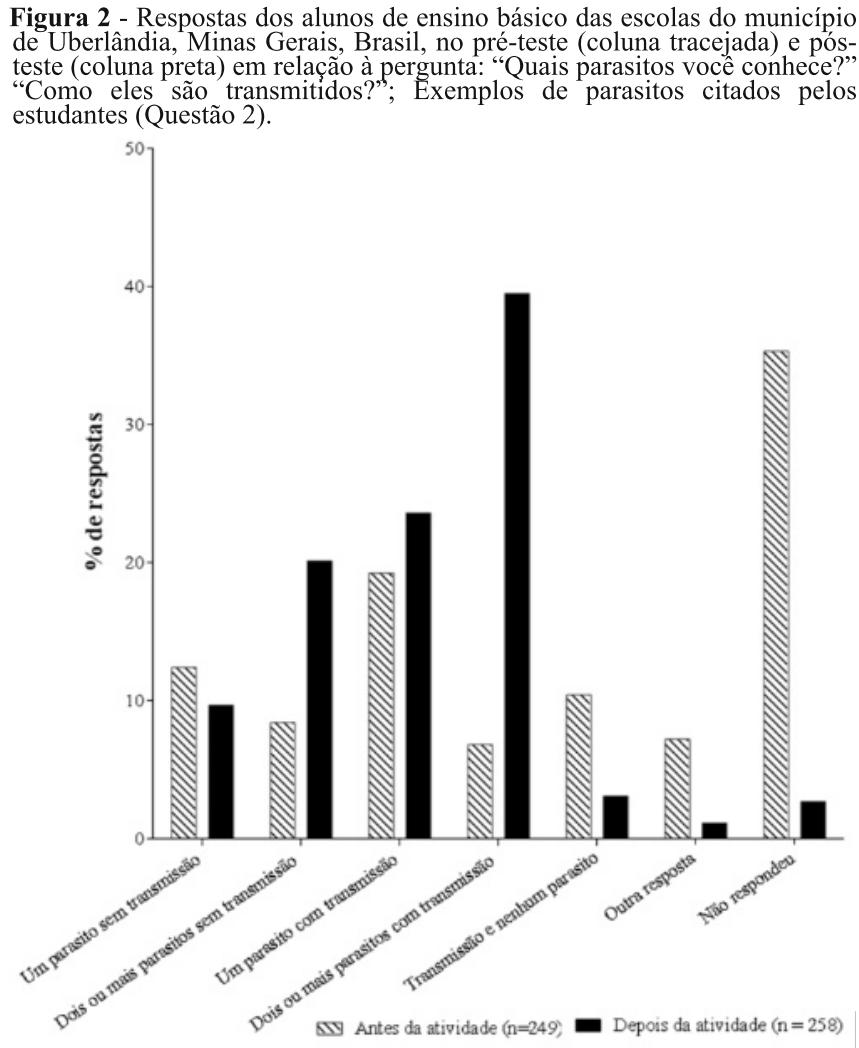

Fonte: Autores.

As parasitoses são tão importantes como qualquer outra doença que não é diagnosticada e tratada precocemente, por isso o conhecimento sobre as principais formas de transmissão e prevenção são essenciais para a saúde pública. De acordo com Malafaia et al. (2013), a compreensão do ciclo de contágio de uma determinada doença auxilia o estabelecimento de atitudes profiláticas favoráveis ao combate da parasitose, como, por exemplo, cuidados básicos de higiene pessoal e doméstica, cuidados com alimentos, água e o ambiente.

Quando perguntado aos alunos "quais parasitos você conhece" (Questão 2), os exemplos mais citados por 35,74\% (89/249), no pré-teste, foram vermes como "solitária" (Taenia spp.), "lombriga" (Ascaris lumbricoides), bicho geográfico (Ancylostoma spp.) e "oxiúros" (Enterobius vermicularis); 6,82\% (17/249) mencionaram ectoparasitos como "bicho de pé" (Tunga penetrans), piolho (Pediculus spp.) e bicheira (miíases); e $0,40 \% \quad(1 / 249)$ mencionou giardíase (Giardia duodenalis); 5,62\% (14/249) mais de um grupo de parasitos, $4,81 \%(12 / 249)$ outra resposta e 46\% (116/249) não responderam a questão.

No pós-teste, observou-se redução na quantidade de discentes que não responderam a questão, 5,42\% (14/258), além disso, 25,58\% (66/258) citaram algum tipo de verme; $24,41 \%(63 / 258)$ algum ectoparasito; $43,02 \%(111 / 258)$ mais de um grupo de parasitos; e 1,55\% (4/258) outra resposta (Figura 3).

Figura 3 - Exemplos de parasitos citados pelos alunos de ensino básico das escolas do município de Uberlândia, Minas Gerais, Brasil, no pré-teste (coluna tracejada e pós-teste (coluna preta) (Questão 2).

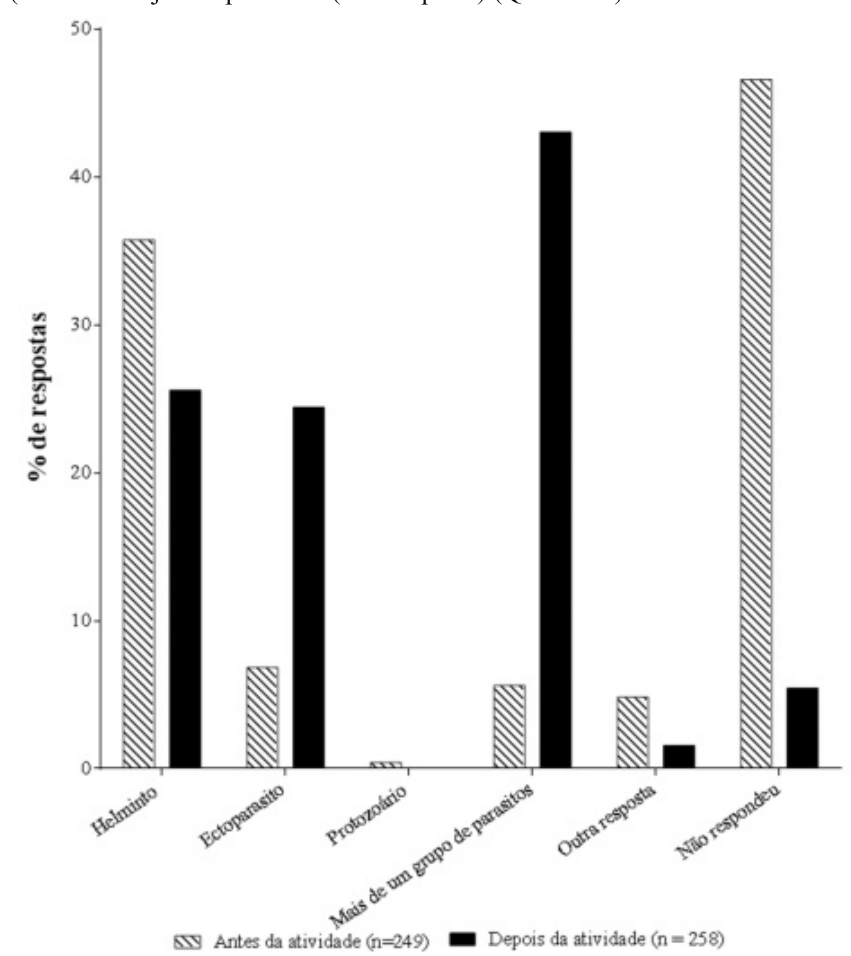

Fonte: Autores.

O conteúdo apresentado em forma de "banner" e contação de histórias veio a confirmar que há maior facilidade do aprendizado quando comparado aos métodos de ensino tradicionais. Esses métodos, além de auxiliarem na aprendizagem, motivaram os alunos a participarem, facilitando o processo pedagógico. Estratégias de ensino que favoreçam a aprendizagem são fundamentais e auxiliam no desenvolvimento do conhecimento (MORAES; TORRES, 2004).

O percentual de alunos que souberam citar uma medida profilática das parasitoses (Questão 3) no préteste foi de $32,93 \%(82 / 249)$, duas ou mais medidas $17,26 \%$ (43/249), 39,35\% (98/249) não responderam a questão e $10,44 \%(26 / 249)$ deram outra resposta. No pós-teste, $5,81 \%(15 / 258)$ dos discentes não responderam a pergunta, e 56,20\% (145/258) citaram duas ou mais medidas profiláticas das parasitoses, enquanto $33,72 \%(87 / 258)$ citaram apenas uma e $4,26 \%(11 / 258)$ deram outra resposta (Figura 4$)$. 
Figura 4 - Respostas dos alunos de ensino básico das escolas do município de Uberlândia, Minas Gerais, Brasil, no pré-teste (coluna tracejada) e pósteste (coluna preta) em relação à pergunta: "Você sabe qual a prevenção para essas doenças?" (Questấo 3).

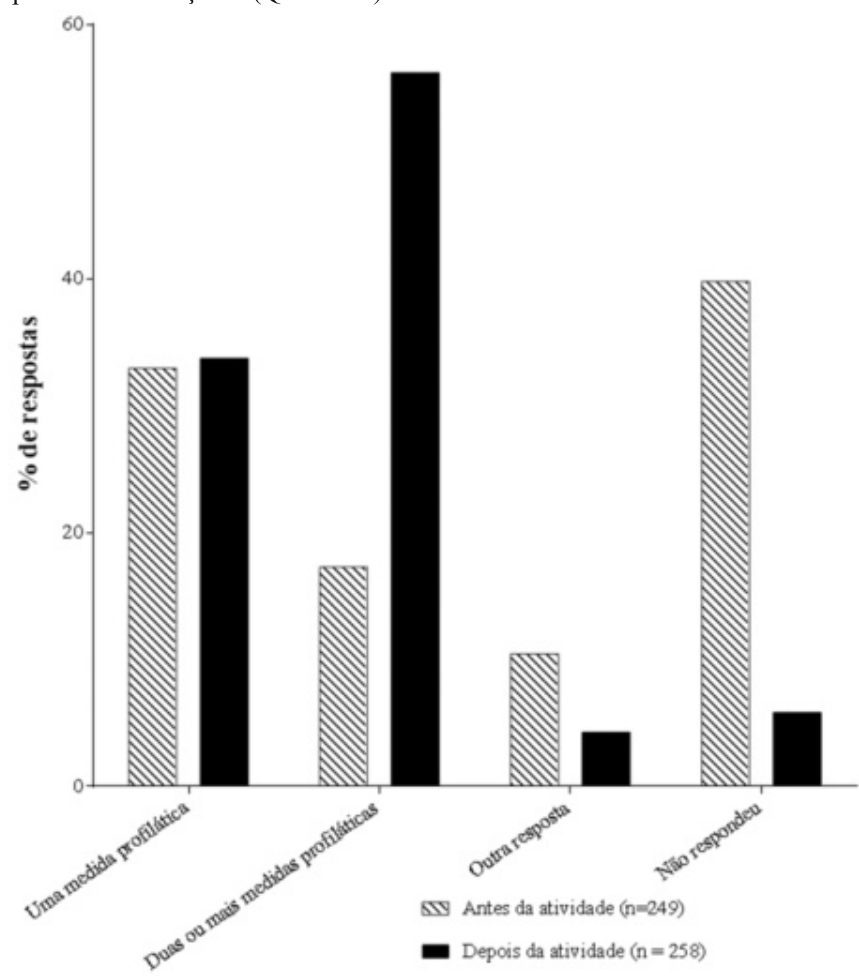

Fonte: Autores.

Durante as palestras, foram enfatizadas as formas de profilaxia das doenças parasitárias e, ao se compararem as respostas entre o pré e pósquestionário, observou-se aumento na porcentagem de alunos que souberam citar mais de uma medida profilática, indicando que a metodologia utilizada foi eficaz para o processo de ensino-aprendizagem. Ressalta-se a importância de trabalhar sobre prevenção de doenças com escolares, pois os mesmos pertencem a um grupo de risco para infecções por parasitos (BELLOTO et al., 2011).

A aprendizagem de hábitos profiláticos de saúde, como os abordados nas palestras ministradas, reduz a prevalência de infecções e, consequentemente, os gastos com atendimento médico e medicamentos. As intervenções educativas auxiliam no controle das infecções levando à melhoria na qualidade de vida do indivíduo (ASOLU; OFOEZIE, 2003; TOSCANI et al., 2007).

Vários pesquisadores têm destacado o papel de ações educativas como ferramenta para prevenir doenças parasitárias, mostrando que práticas educativas são tão eficazes quanto o saneamento básico e superiores, quando comparado ao tratamento em massa em longo prazo (TOSCANI et al., 2007; FALAVIGNA-GUILHERME et al., 2002). No Brasil, há relatos de várias experiências bem-sucedidas de educação para prevenção de doenças parasitárias (BOEIRA, 2010; DIAS; KOVALICZN, 2014; LIMA et al., 2017).

Intervenções pedagógicas que utilizam metodologias alternativas como cartilhas educativas, brincadeiras, teatros e que têm como foco os cuidados essenciais de higiene pessoal e dos alimentos são métodos eficazes para a compreensão e posterior prevenção da transmissão de doenças (BERNARDES, 2016; BOEIRA, 2010; LUDWIG, 2012).
Os questionários aplicados antes e após a ação extensionista confirmaram o crescente aproveitamento dos alunos. Observou-se que o número de respostas corretas aumentou, confirmando que a intervenção foi capaz de modificar a concepção dos alunos em relação ao conteúdo abordado. Este trabalho corrobora com Lima et al. (2017), que verificaram o conhecimento prévio dos alunos sobre parasitoses, através de préteste, observando que foi baixo quando comparado com o pós-teste, aplicado após a intervenção educativa, indicando a importância da inserção de projetos de extensão nas escolas.

De acordo com Armendoeira (2002), a diversidade de enteroparasitoses em alunos é indicador da falta de informação da população sobre hábitos e condições propícias para a transmissão desses parasitos. A escola é instituição que desempenha papel importante na educação e formação da criança e do adolescente. Essa instituição é considerada veículo de transformação da sociedade, pois ações pedagógicas geram condições eficazes para o desenvolvimento de comportamentos que se apliquem à vida sociopolítica.

\section{Conclusão}

Após o desenvolvimento das atividades de extensão com os alunos de educação infantil, ensino fundamental e médio, foi possível constatar um processo de ensino-aprendizagem satisfatório, pois observou-se melhoria no esclarecimento do público-alvo sobre a importância da educação sanitária no controle e prevenção de doenças parasitárias, o que ficou evidente através dos resultados dos questionários aplicados antes e após o desenvolvimento das atividades.

As ações despertaram nos envolvidos o conhecimento e atitudes sobre as estratégias de educação em saúde. E considerando a participação dos alunos, pode-se concluir que o tema abordado foi interessante e bem recebido pelos mesmos.

\section{Referências}

ALVES, M. L. et al. Cartilha educativa em quadrinhos como instrumento de divulgação científica sobre leishmanioses no Rio Grande do Norte. Revista da SBEnBio, São Paulo, n. 72014, p. 5428-5436, out. 2014.

ARMENDOEIRA, M. R. R. et al. Estudo das enteroparasitoses em escolares da Rede Pública de Cascadura - Rio de Janeiro. Revista Souza Marques, v. 1, 2002.

ASOLU, S. O.; OFOEZIE, I. E. The role of health education and sanitation in the control of helminth infections. Acta Tropica, v.86, n.2, p.283-94, 2003.

BEINNER, M. A.; ROCKSANE, C. N.; LAMOUNIER, J. A. Prevalência da infecção por parasitas intestinais em crianças pré-escolares de distritos rurais do município de Diamantina, Minas Gerais. Revista Médica de Minas Gerais, v. 16, n. 2, p. 84-7, 2006. 
BELLOTO, M. V. T. et al. Enteroparasitoses numa população de escolares da rede pública de ensino do Município de Mirassol, São Paulo, Brasil. Revista PanAmazônica de Saúde, v. 2, n. 1, p. 37-44, 2011.

BERNARDES, L. S. et al. Uso de metodologias alternativas no ensino de Ciências: um estudo realizado com o conteúdo de serpentes. Ensino, Saúde, Ambiente, Niterói, v. 9, n. 1, abr. 2016.

BETHONY, J. et al. Soil-transmitted helminth infections: Ascariasis, trichuriasis, and hookworm. Lancet, v. 367, n. 9521, p. 1521-32, maio 2006.

BOEIRA, L.V. et al. Educação em saúde como instrumento de controle de parasitoses intestinais em crianças. Revista Varia Scientia, v. 9, n. 15, jan./jul. 2010.

BRASIL. Instituto Brasileiro de Geografia e Estatística (IBGE). Diretoria de Pesquisa, Coordenação de População e Indicadores Sociais. NOTA 1: Estimativas da população residente com data de referência $1^{\circ}$ de julho de 2013 . Disponível em: https://cidades.ibge.gov.br/brasil/mg/uberlandia/panorama. Acesso em: 14 ago. 2018.

CHIZZOTTI, A. Pesquisa em Ciências Humanas e Sociais. 5. ed. São Paulo: Cortez, 2001.

DIAS, C. A. C.; KOVALICZN, R.A. Parasitoses humanas e o uso de recursos midiáticos na aprendizagem. In: CADERNOS PDE. Os desafios da escola pública paranaense na perspectiva do professor PDE. v.1. Curitiba, 2014.

FALAVIGNA-GUILHERME, A.L. et al. Atividades educativas para o controle de triatomíneos em área de vigilância epidemiológica do Estado do Paraná, Brasil. Cadernos de Saúde Pública, v.18, n.6, p.1543-50, nov./dez. 2002.

FERREIRA, P. et al. Occurrence of intestinal parasites and comensal organisms among school children living in a 'land less farm workers' settlement in Campo Florido, Minas Gerais, StateBrazil. Revista da Sociedade Brasileira de Medicina Tropical, v.36, n. 1, p. 109-111, jan./fev. 2003

GALVANI, A. P. Age-dependent epidemiological pattern sands train diversity in helminth parasites. Journal of Parasitology, v. 91, n. 1, p. 24-30, fev. 2005.

GONÇALVES, A. L. R. et al. Prevalence of intestinal parasites in pre school children in the region of Uberlândia, State of Minas Gerais, Brazil. Revista da Sociedade Brasileira de Medicina Tropical, v. 44, n. 2, p. 191-193, mar./abr. 2011

KUMAR, P. et al. Coccidian intestinal parasites among immunocompetent children presenting with diarrhea: Are we missing them? Tropical Parasitology, v. 7, n. 1, p. 37-40, jan./jun. 2017

LEITE, L. S. Mídia e a Perspectiva da Tecnologia Educacional no Processo Pedagógico Contemporâneo: A contemporaneidade e o processo sociotécnico, In: FREIRE, Wendel et al (Org.). Tecnologia e Educação: As mídias na prática docente. 2. ed. Rio de Janeiro: Wak, 2011.

LIMA, C. M. B. L. et al. Intervenção educativa no conhecimento das geo-helmintíases em escola municipal. Revista Ciência em Extensão, v.13, n.1, p. 91-101, 2017.

LUDWIG, K. M. et al. Enteroparasitoses em um bairro da cidade 275 de Cândido Mota SP. Journal of the Health Sciences Institute, v. 30, n. 3, p. 271-6, 2012.
MACHADO, E. R.; SANTOS, D. S.; COSTA-CRUZ, J. M. Enteroparasites and commensals among children in four peripheral districts of Uberlândia, State of Minas Gerais. Revista da Sociedade Brasileira de Medicina Tropical, v.41, n.6, p. 581-585, nov./dez. 2008.

MACIEL, L. R. Política Nacional de Extensão: perspectivas para a universidade brasileira. Revista Participação, Brasília, n.18, p.17-27, dez. 2010.

MALAFAIA, G. et al. Conhecimentos de discentes do Ensino Fundamental e Médio de uma escola pública de Urutaí (Goiás) sobre doenças intestinais. Revista Saúde e Pesquisa, v. 6, n. 2, p. 237-47, 2013.

MASSARA, C. L. et al. Geo-helmintos. 2018. Disponível em: www.xistose.com. Acesso em: 06 jul. 2018.

MENEZES, A. L. et al. Prevalence of intestinal parasites in children from public day care centers in the city of Belo Horizonte, Minas Gerais, Brazil. Revista do Instituto de Medicina Tropical de São Paulo, v. 50, n. 1, p. 57-59, jan./fev. 2008.

MENDES, G. G. et al. Headlice in schoolchildren in Uberlandia, Minas Gerais state, Brazil. Revista de Patologia Tropical, v. 46, n. 2, p. 200-208, jun. 2017.

MOITA, F. M. G. S. C.; ANDRADE, F. C. B. EnsinoPesquisa-Extensão: um exercício de indissociabilidade na pós-graduação. Revista Brasileira de Educação, Rio de Janeiro, v.14, n. 41, p. 269-393, mai./ago. 2009.

MONTEIRO, A. M. C. et al. Parasitoses intestinais em crianças de creches públicas localizadas em bairros periféricos do município de Coari, Amazonas, Brasil. Revista de Patologia Tropical, v. 38, n. 4, p. 284-290, out./dez. 2009.

MORAES, M. C.; TORRE, S. Sentipensar: fundamentos e práticas para reencantar a educação. Petrópolis/RJ: Vozes, 2004.

NOBRE, L. N. et al. Risk factors for intestinal parasitic infections in preschoolers in a low socio-economica, Diamantina, Brazil. Pathogens and Global Health, v. 107, n. 2, p.103-106, 2013.

PAIM, A. S.; IAPPE, N. T.; ROCHA, D. L. B Metodologias de ensino utilizadas por docentes do curso de enfermagem: enfoque na metodologia problematizadora. Revista Eletrônica trimestral de Enfermaria, n. 37, 2015.

PEREIRA E. B. et al. Detection of intestinal parasites in the environments of a public school in the town of Diamantina, Minas Gerais state, Brazil. Revista do Instituto de Medicina Tropical de São Paulo, p. 58-51, jul. 2016.

PMU. Prefeitura Municipal de Uberlândia. Relação das Unidades Escolares. Disponível em: www.uberlandia.mg.gov.br/?pagina $=$ Conteudo\&id $=76$. Acesso em: 14 ago. 2018.

REZENDE, C. H. A.; COSTA-CRUZ, J. M.; GENNARICARDOSO, M. L. Enteroparasitoses em manipuladores de alimentos de escolas públicas em Uberlândia (Minas Gerais), Brasil. Revista Panamericana de Salud Pública, v.2, p. 392-397, 1997.

SILVA, J. J. et al. Enterobiasis and other intestinal parasitoses in childrenattending educacional institutions in Uberlândia, State of Minas Gerais, Brazil. Revista de Patologia Tropical, v.32, p. 87-94, jan./jun. 2003. 
SRE. Secretária Regional de Educação. Relação de Estabelecimentos de Ensino ativo em Minas Gerais. Disponível em: www2.educacao.mg.gov.br/parceiro/listade-escolas. Acesso em: 14 ago. 2018.

TOSCANI, N. V. et al. Desenvolvimento e análise de jogo educativo para crianças visando à prevenção de doenças parasitológicas. Interface-Comunicação, Saúde, Educação, v. 11, n. 22, p.281-294, 2007.
UCHÔA, C. M. A. et al. Parasitoses Intestinais: prevalência em creches comunitárias da cidade de Niterói, Rio de Janeiro, Brasil. Revista do Instituto Adolfo Lutz, v. 60, n. 2, p. 97-101, 2001.

WHO. WORLD HEALTH ORGANIZATION. Intestinal worms, epdemiology. Disponível em:

http://www.who.int/intestinal_worms/epidemiology/en/. Acesso em: 26 jun. 2018. 